\title{
A Portable Virtual LAB for Informatics Education using Open Source Software
}

\author{
MILAB \\ Ali H. Alharbi, PhD. \\ The Department of Health Informatics, College of Public Health and Health Informatics \\ Qassim University \\ Albukairiyah, Qassim
}

\begin{abstract}
The need for students to have hands-on experience is very important in many disciplines to match the requirements of today's dynamic job market. Informatics, which is the science of information engineering, has been recently integrated into many academic programs. Teaching students the main skills in modern software and web development is essential for them to be successful informatics professionals. For any informatics program, students engage in working on projects as essential parts for some courses in their academic programs. This paper presents the development and evaluation of MiLAB (My Mobile Informatics Lab), a portable virtual lab environment for the teaching and learning of modern web development skills. MiLAB has been integrated into an undergraduate health informatics academic program to improve the teaching and learning of essential web development skills, such as databases management and customization of modern content management systems. The evaluation of MiLAB indicated that it served as an interactive personal environment for students to implement, collaborate, and present their web development projects. Strengths, weaknesses and possible improvements are also discussed.
\end{abstract}

Keywords_Virtual labs; open source software; e-learning

\section{INTRODUCTION}

It is essential for undergraduate informatics academic programs to include hands-on experience in order to prepare students for the real world jobs. Traditionally, academic institutions rely on physical computer labs that are equipped with essential software to teach students various skills on computing and informatics. However, with limited educational resources and dramatically increasing number of students, efficient and timely access to physical computer labs becomes more difficult. The use of information and communication technology to support education has led to the emergence of innovative paradigms for teaching and learning.

Simulation and virtualization tools provide effective and alternative approaches to help students gain essential informatics skills without the need to be in a physical computer lab [1]. However, this technology is not widely implemented by educators due to the difficulties associated with the integration into the learning environment [2]. One of the key success factors for the use of simulations in education is the integration of these simulations into the traditional teaching and learning environment. Virtual Labs can be defined as "E- learning platforms where learners can gain the experience of practical experimentation without any direct physical involvement on real bench work" [3]. Also, some studies have used the term virtual labs to refer to the concept of providing distance access to physical labs to support the learning in some disciplines, such as physics and engineering [4]. In computer science and informatics education, virtual labs can provide safe and customizable learning environments for students to gain hands-on experience on various skills, such as networking, programming and web development, at any time and place [5][7]. However, when it comes to cost, the current technology used in the design and implementation of virtualization and simulation does not come without a high cost [8].

Open Source Software (OSS) has achieved wide adoption in various domains, such as server technologies, networking, databases and enterprise tools. OSS refers to software that complies with the following criteria [9]:

- Free to redistribute.

- The source code is freely available for modification.

OSS leading products such as Apache, MySQL, along with programming languages, such as PHP, Java and Perl are among the technologies that have contributed to the success of the internet.

OSS plays important roles to improve teaching and learning in various disciplines, such as computer science, information systems and science [10], [11].

This paper gets insights into the educational effectiveness of open-source software in creating constructivist educational environments for teaching modern web development. To achieve this, the paper proposes a portable virtual learning lab, MiLAB (My Mobile Informatics Lab), that can be used as a simulated environment for informatics education. As a proveof-concept, MiLAB was used to teach modern techniques in web development for undergraduate health informatics students. Health informatics is an emerging discipline that combines computer and information science along with health and biomedical science to support healthcare systems. Teaching health informatics requires that candidates gain practical experience on different information systems. 


\section{RELATED WORK}

\section{A. Virtual Labs in Education}

Different approaches have been proposed in the literature to design virtual labs for educational purposes in various academic disciplines. For example, in engineering education, various applications and methods have been proposed to use virtual and remote labs to enhance teaching and learning about different engineering topics, such as digital signal processing [12].

In computer science education, virtual labs have been used to augment teaching and learning in various courses. For example, $\mathrm{Wu}$, et al. [13] presented a virtual computer lab that was designed to allow students to experiment with various information security approaches via a computer network constructed using virtual machines. The environment gives students the opportunity to apply various concepts in a simulated environment without compromising any computer network. Another approach was presented by Kumar, et al. [14], in which a cloud-based virtual lab solution has been used to teach students various computer science concepts.

\section{B. Open Source Software in Education}

The open source movement has affected many aspects of our life today including education. As academic institutions move towards reducing cost and increasing efficiency, it is critical for educators to find alternative and efficient tools to supplement education. Open Source Software (OSS) is one of the viable alternative that academic institutions and educators should think about to achieve this vision. In higher education, based on open and free source frameworks, a number of notable educational software has emerged. Moodle [15], the most well-known open source learning management system, has been extensively adopted in higher education and has an active and large community. It provides different pedagogical tools to help improve the quality of e-learning. Atutor [16] is another open source learning management system, which also gains increased interest and provides the basic functions required to design and manage e-learning contents.

Open source software plays important role to improve education [17]. For example, in computer science education, there are different computer-supported tools and educational resources available for students and educators. However, despite being perceived as educationally effective, these tools and resource are not widely adopted by computer science educators. Previous research, such as [18], [19], relates this problem to the fact that teachers are too busy to find and integrate these tools into the teaching environment, as well as they do not have time to teach students to learn how to use such tools.

In engineering education, Froyd, et al. [20] identified five major shifts that affected the discipline in the last few years. In the fifth shift, the authors pointed out that "technologies (e.g., the Internet, intelligent tutors, personal computers, and simulations) have been predicted to transform education for over 50 years" [19].

\section{PORTABLE VIRTUAL LAB FOR INFORMATICS EDUCATION (MILAB)}

This section describes in detail MiLAB, a proposed portable virtual lab for teaching and learning of informatics skills. MiLAB utilizes the state-of-the-art in open source software platforms to provide a portable, virtual, adaptive and personalized environment that can be used for teaching and learning of important web development skills. These skills include web development, content management, and designing and maintaining databases.

A lightweight server was deployed into a USB flash drive, with essential functionality so each student can experiment with a range of OSS platforms in a fully simulated environment. This USB flash drive serves as a personalized lab that is customized for each student's needs and preferences.

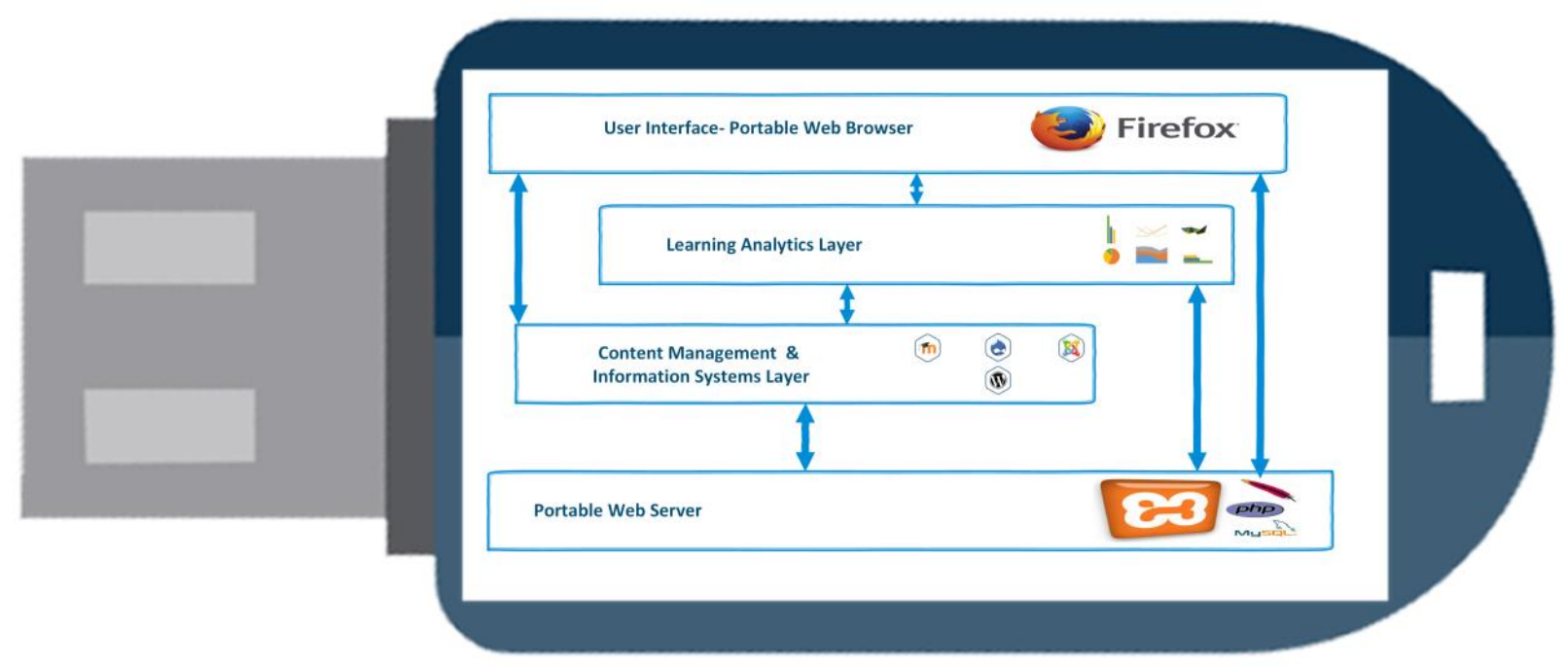

Fig. 1. Architecture of the Portable Virtual Informatics LAB (MiLAB). 
The architecture of MiLAB, as depicted in Fig. 1, consists of the following components:

\section{A. Portable Lightweight Web Development Server}

The underlying server of this virtual lab is based on XAMPP [21] , a simple, lightweight, free and open source Apache web server distribution that makes it easy to setup and run local web development servers. XAMPP stands for CrossPlatform, Apache, MariaDB, PHP and Perl. It is a crossplatform in the sense that it can work under any operating system. XAMPP serves as a container that hosts all components of the virtual lab. It also provides a control panel for administrators to manage and monitor the lab.

\section{B. Content Management and Information Systems Platforms}

This layer serves as the underlying infrastructure to deploy and manage various open source content management systems, as well as other open source information systems. All these platforms share the same underlying server on which different databases can be created and linked to the open source platforms. Students can customize these platforms to meet needs and preferences. Plug-ins and additional modules can be installed on each system to enhance the functionality when needed.

\section{Learning Analytics Module}

One of the most important components of this virtual lab is a learning analytics module designed to provide insight into the learning process. This module provides a wide range of features to support monitoring of the educational process. The module allows educators and learners to generate different kinds of reports and statistics.

Analytics is a general term that focuses on the use of data and statistical analysis techniques to gain insight into specific issues. Learning Analytics (LA) is an emerging research area that focuses on the retrieval and analysis of data to support teaching and learning [22]. There has been an increasing interest in the analysis of data generated from students' interaction with various learning tools. One of the reasons behind this interest is the great potential for this analysis to discover students' behavior patterns that helps design and deliver adaptive learning contents.

IV. Evaluation of Milab in Practice: A Portable 'VIRTUAL PLATFORM FOR HEALTH INFORMATICS STUDENTS' PROJECTS

\section{A. Methodology}

MiLAB was used to improve the teaching and learning of modern web development skills in an undergraduate academic program of Health Informatics. In this program, it is essential for students to be familiar with modern web development techniques, including the customization and management of modern information system applications. MiLAB was used as a portable virtual infrastructure for students to work on their projects individually and in groups.

In the first few weeks of the course, the focus was put on the installation and customization of the portable server. A number of lab sessions have introduced students to the technology of web servers and how to deploy a simple, local and portable web server in a USB flash memory. At the end of the sessions, students successfully installed the portable server and they were familiar with its control panel. In addition to this, students also learnt how to create and manage MySQL databases.

After that, students were introduced to a number of wellknown content management frameworks to be used later for students' health informatics projects. In this phase, students learnt how to install and setup each content management system and customize it to support health informatics projects. This study adopted WordPress and Drupal, both of which are well-established and sophisticated content management systems.

The instructor guided students through the process of setting up a database for each content management system, and deploying each system to work as a portable application on the server. This phase covers different functionality of the content management system, including but not limited to, themes, menus, content editing, user management, and plugins installation.

The system was used from 2016 to early 2018 at the College of Public Health and Health Informatics, Qassim University in Saudi Arabia. The main objective of this study is to get insight into the potential benefits for the proposed portable virtual lab as a pedagogical tool to improve teaching and learning of modern web development, particularly in health informatics education. The main research questions that this study is intended to answer can be summarized in the following:

1) To what extent do students accept MiLAB as a pedagogical tool to improve learning and teaching?

2) What are the strengths, weaknesses and possible improvements for MiLAB from the students' point of view?

\section{B. Study Participants}

The subjects of the study were students from the undergraduate program of Health Informatics at College of Public Health and Health Informatics, Qassim University, Saudi Arabia. The study was conducted using patches of students in the period from 2016 to early 2018 . Voluntarily, 64 students participated to complete the questionnaire, which is described in the section below.

\section{Data Collection Instrument}

A questionnaire, with both closed and open-ended questions, was administered to students at the end of the study.

The quantitative part of the questionnaire was adapted from the Unified Theory of Acceptance and Use of Technology (UTAUT) [23]. UTAUT is an extension to the original Technology Acceptance Model (TAM), an instrument used to predict users' acceptance of a technology on the basis of a number of constructs. UTAUT, which was originally developed by Venkatesh, et al. [23], has been described as a cost-effective and easy-to-use questionnaire for predicting user's acceptance of different systems.

UTAUT assumes that user's acceptance of a technology is affected by a number of constructs. Six constructs were 
adopted in this study. Table I describes these constructs as reported in [23].

TABLE I. DEFINITIONS OF THE CONSTRUCTS ADOPTED FROM THE UTAUT MODEL

\begin{tabular}{|c|c|}
\hline Construct & Definition ( in the context of MiLAB) \\
\hline $\begin{array}{l}\text { Performance } \\
\text { Expectancy (PE) }\end{array}$ & $\begin{array}{l}\text { The degree to which an individual believes that } \\
\text { using MiLAB would enhance his/her learning. }\end{array}$ \\
\hline Effort Expectancy (EE) & $\begin{array}{l}\text { The degree to which an individual believes that } \\
\text { MiLAB is easy to use. }\end{array}$ \\
\hline $\begin{array}{l}\text { Facilitating Conditions } \\
\text { (FC) }\end{array}$ & $\begin{array}{l}\text { The degree to which the user believes that } \\
\text { technical infrastructure and resources are } \\
\text { available to support the use of MiLAB. }\end{array}$ \\
\hline Self-Efficacy (SE) & $\begin{array}{l}\text { Judgment of one's ability to use MiLAB to } \\
\text { accomplish a particular task. }\end{array}$ \\
\hline $\begin{array}{l}\text { Attitudes towards using } \\
\text { the Technology (A) }\end{array}$ & The motivation and willingness to use MiLAB. \\
\hline $\begin{array}{l}\text { Behavioral Intention to } \\
\text { Use the System (BI) }\end{array}$ & $\begin{array}{l}\text { The user positive or negative intention to use } \\
\text { MiLAB. }\end{array}$ \\
\hline
\end{tabular}

\section{RESUlTS AND DisCUSSION}

This section outlines and discusses the results of students' responses to the questionnaire. Descriptive statistics techniques were applied to get insight into the extent to which students' support using MiLAB to enhance the teaching and learning environment.

\section{A. User's Acceptance of MiLAB}

Fig. 2 to 7 show the distribution of students' responses to each construct in the questionnaire using a 7-point Likert scale ranging from 1( strongly disagree) to 7 (strongly agree).

In the Performance Expectancy construct, as appears in Fig. 2, the vast majority of students (79\%) strongly believed that using MiLAB would enhance their learning. They believed the system would enhance their productivity and help them accomplish tasks more quickly and efficiently.

Fig. 3 shows the distribution of students' responses to the Effort Expectancy construct. Half of students believed that MiLAB was easy to use for them. They believed they would be skillful at using the system. However, $13 \%$ of the students slightly disagreed and expected they will face difficulties interacting with MiLAB smoothly.

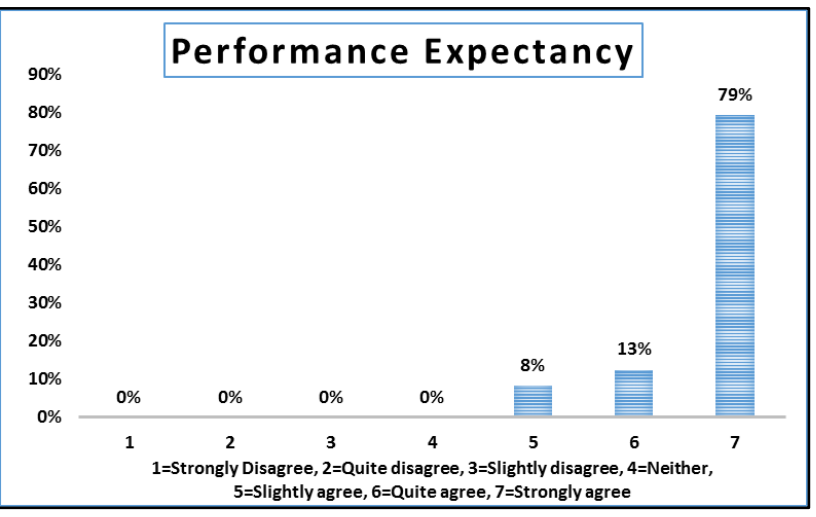

Fig. 2. The distribution of students' responses to the Performance Expectancy construct.

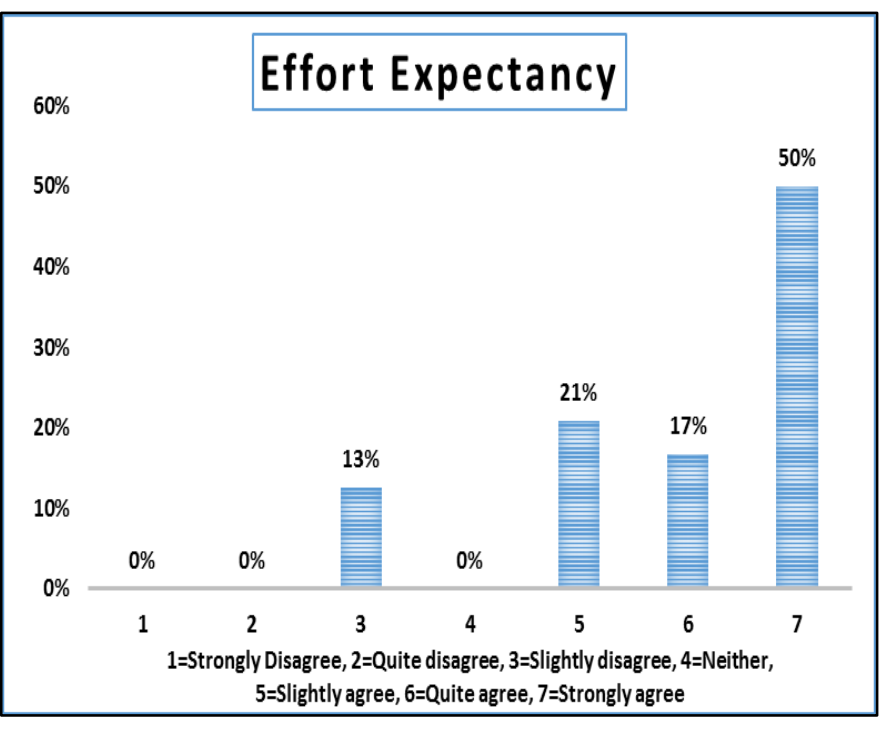

Fig. 3. The distribution of students' responses to the Effort Expectancy construct.

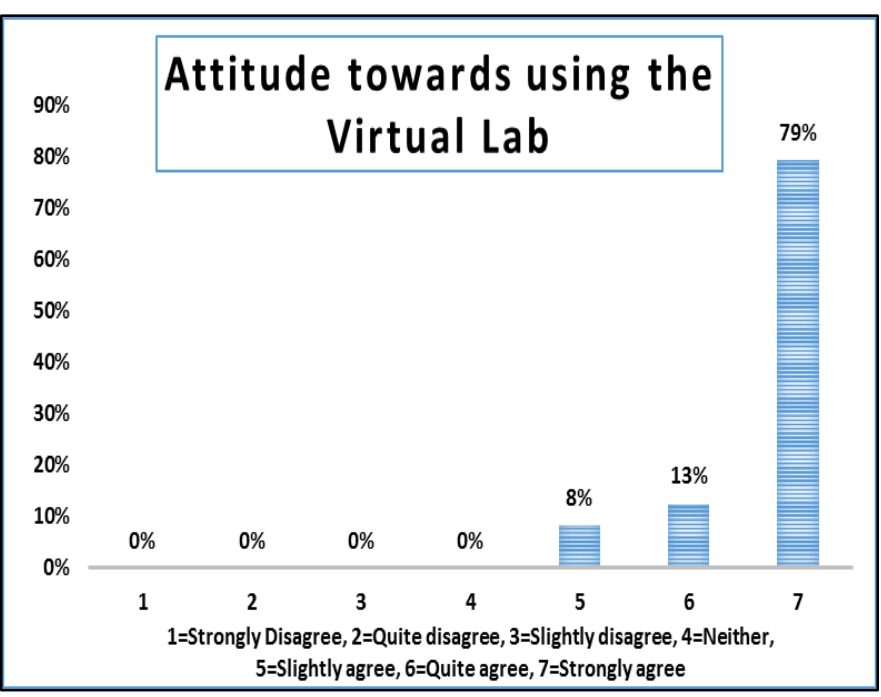

Fig. 4. The distribution of students' responses to the Attitude towards using MiLAB

Fig. 4 summarizes students' attitudes towards using MiLAB. The result reflects a positive attitude towards using the virtual lab, with (79\%) of the students reported that using the system was interesting and motivated them to engage with the learning material and tasks.

Fig. 5 shows the result of students' responses regarding the availability of adequate resources and support to use the virtual lab efficiently. (42\%) of the students strongly believed that enough technical support and resources were available for them. However, $(16 \%)$ of the students believed that they do not have the required resources available to support them when they face difficulties. It is also worth noting that (13\%) of the students were not sure about the availability of resources or technical support to improve the use of the virtual lab. 


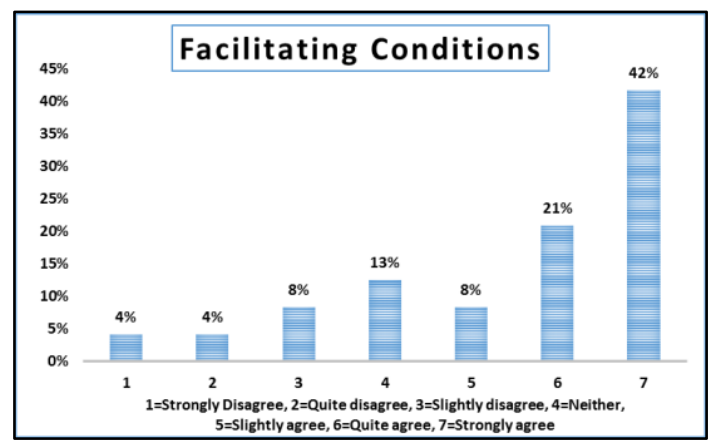

Fig. 5. The distribution of students' responses to the facilitating conditions construct.

Self-Efficacy construct measure the students' judgment of their ability in using the virtual lab. As shown in Fig. 6, the vast majority of students were confident about their ability to use MiLAB to accomplish learning tasks (54\% strongly agree, $13 \%$ quite agree and $8 \%$ slightly agree).

Fig. 7 shows the distribution of students' responses to the questions measuring their behavioral intention to use MiLAB. Almost all students reported that they have a positive intention to use the virtual lab during their study.

Overall, MiLAB received high ratings in almost all aspects as measured by the UTAUT questionnaire. Responses to the questionnaire show that students have the motivation and intention to use the portable virtual lab in their study and selfregulated learning. However, some responses indicated that students do not have enough resources to help them in learning how to use the system efficiently.

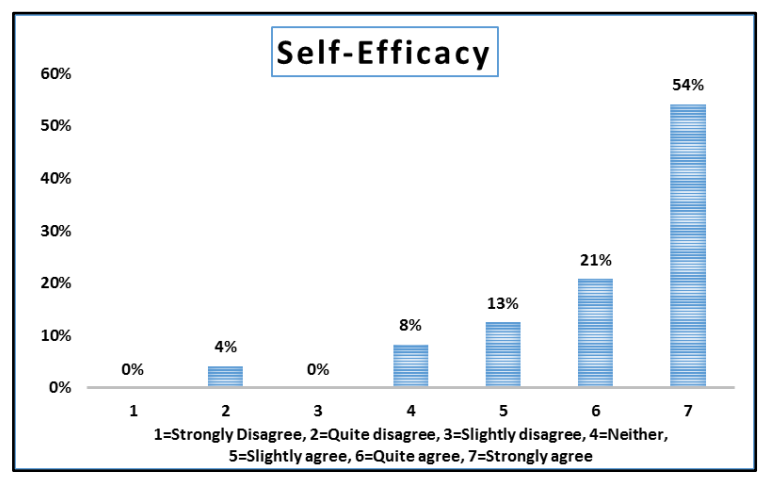

Fig. 6. The distribution of students' responses to the Self-Efficacy construct.

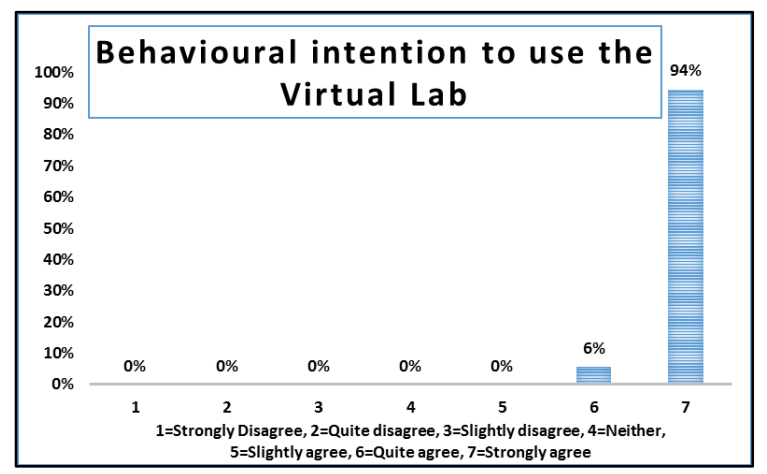

Fig. 7. The distribution of students' responses to the Behavioral intention to use MiLAB.

\section{B. Strengths and Weaknesses}

The analysis of the open-ended questions revealed a number of factors that affected the adoption and acceptance of MiLAB from students' point of view. This section outlines the strengths, weaknesses and areas of possible improvement for MiLAB elicited from students' responses to the open-ended questions.

As summarized in Table II, students believed that one of the most important features of MiLAB is that it was easy to use, learn and navigate. However, some students believed that MiLAB needs more functions, and in its current version, only few are available. It is also stressed by students that MiLAB can serve as a reference for their projects and work at other courses, which in turn has the potential to increase their productivity. Moreover, from the students' point of view, MiLAB was interactive and it supported group projects. This enhances students' ability and motivation to collaborate with other group members and serves as a platform for generating and testing new ideas.

Life-long learning is one the most important characteristic of learners in the new era. Based on students' responses, MiLAB had the ability to help students learn individually on their own base to improve web development skills. Students also think that the system will help them improve their career in the future. However, to do this, some weaknesses of the system need to be considered. These weaknesses, as descried in Table III, include stability problems and some hardware compatibility issues.

TABLE II. STRENGTHS OF MiLAB FROM THE STUdENTS' POINT OF VIEW

\begin{tabular}{|l|l|}
\hline Strength & Examples \\
\hline Easy to Use & $\begin{array}{l}\text { - Easy to setup } \\
\text { - Navigation was clear } \\
\text { - Easy to learn }\end{array}$ \\
\hline Improve Productivity & $\begin{array}{l}\text { - The system serves as a reference in many } \\
\text { courses }\end{array}$ \\
\hline $\begin{array}{l}\text { Interesting and } \\
\text { Interactive }\end{array}$ & $\begin{array}{l}\text { - Transformation to traditional lectures. } \\
\text { - Increasing motivation to learn }\end{array}$ \\
\hline Support Collaboration & $\begin{array}{l}\text { - Supporting group projects } \\
\text { - A platform to generate and test ideas }\end{array}$ \\
\hline $\begin{array}{l}\text { Support Life-Long } \\
\text { Learning }\end{array}$ & $\begin{array}{l}\text { - Helping students learn outside the course } \\
\text { - Supporting students in their future career }\end{array}$ \\
\hline
\end{tabular}

TABLE III. WEAKNESSES OF MILAB FROM THE STUDENTS' POINT OF VIEW

\begin{tabular}{|c|c|}
\hline Weakness & Examples \\
\hline $\begin{array}{l}\text { Limited } \\
\text { Functionality }\end{array}$ & $\begin{array}{l}\text { - Only few functions were available. } \\
\text { - Adding new functions requires plug-ins. }\end{array}$ \\
\hline $\begin{array}{l}\text { Hardware } \\
\text { problems }\end{array}$ & $\begin{array}{l}\text { - The system is based completely on an external USB } \\
\text { memory drive. } \\
\text { - Some PCs block the server. }\end{array}$ \\
\hline Stability & $\begin{array}{l}\text { - The server sometimes does not start properly. } \\
\text { - Some programs may affect how the server works. }\end{array}$ \\
\hline
\end{tabular}


TABLE IV. AREAS OF IMPRovemENT to the Portable ViRTUAL LAB EXTRACTED FROM STUDENTS’ RESPONSES

\begin{tabular}{|l|l|}
\hline $\begin{array}{l}\text { Area of } \\
\text { improvement }\end{array}$ & Examples \\
\hline Localization & $\begin{array}{l}\bullet \text { Easy language switch } \\
\text { - Translations }\end{array}$ \\
\hline Availability & $\begin{array}{l}\bullet \text { Cloud-based } \\
\bullet\end{array}$ \\
\hline Technical Support & $\begin{array}{l}\text { Dedicated system that is fully supported } \\
\text { by the IT department }\end{array}$ \\
\hline $\begin{array}{l}\text { Customization and } \\
\text { Upgrade }\end{array}$ & $\begin{array}{l}\bullet \text { Usable user interface } \\
\bullet\end{array}$ \\
\hline
\end{tabular}

\section{Areas of Improvement}

Students were given the opportunity to reflect on their experience using MiLAB as a learning tool. Free text responses by students on this question have yielded a number of potential areas of improvement to the design of MiLAB. These are summarized in Table IV.

From the students' point of view, the system needs to support easy customization and localization to meet students' preferences. For some students, it was not easy to add new language support and it was difficult to author multilingual contents in the content management system. It is also noted by students that adding new features is not easy, and there is no instructions to guide them on how to install new plug-ins and modules. From students' responses, it was clear that MiLAB should be accompanied with a dedicated technical support section to provide necessary assistance to students all the time. Finally, as MiLAB is completely based on an external USB hard drive, compatibility and hardware issues arise. To use the system, students need to carry their own external USB drive all the time to work offline. It is recommended to provide an online version of MiLAB as a cloud-based service.

\section{CONCLUSION}

Open source software plays significant roles in education in many disciplines. This paper discussed the design, implementation and evaluation of MiLAB (My Mobile Informatics $\mathrm{LAB}$ ), a proposed portable virtual $\mathrm{LAB}$ for the teaching and learning of web development skills using Open Source Software technologies. The proposed virtual lab was then used to teach web development skills for health informatics students. The results of the study showed that MiLAB could serve as an easy and flexible tool for students to gain hands-on experience in informatics skills. However, the study pointed out that there are several challenges that face the adoption of portable virtual labs as educational tools, including compatibility and stability issues as well as lack of technical support.

\section{REFERENCES}

[1] I. Al Saeed and M. Eugene Dawson, "Use of Open Source Software and Virtualization in Academia to Enhance Higher Education Everywhere," in Increasing Student Engagement and Retention Using Immersive Interfaces: Virtual Worlds, Gaming, and Simulation, ed, pp. 283-313.

[2] F. Lateef, "Simulation-based learning: Just like the real thing," Journal of Emergencies, Trauma and Shock, vol. 3, p. 348, 2010.
[3] S. Ray, N. R. Koshy, P. J. Reddy, and S. Srivastava, "Virtual Labs in proteomics: New E-learning tools," Journal of proteomics, vol. 75, pp. 2515-2525, 2012.

[4] J. Ma and J. V. Nickerson, "Hands-on, simulated, and remote laboratories: A comparative literature review," ACM Computing Surveys (CSUR), vol. 38, p. 7, 2006.

[5] I. Branovic, D. Markovic, R. Popovic, V. Tomasevic, and D. Zivkovic, "Development of modular virtual lab for introductory computing courses," in Global Engineering Education Conference (EDUCON), 2013 IEEE, 2013, pp. 1027-1031.

[6] V. Baljak and S. Honiden, "Discovery of configurations for indoor wireless sensor networks through use of simulation in virtual worlds," in Sensor Technologies and Applications (SENSORCOMM), 2010 Fourth International Conference on, 2010, pp. 323-328.

[7] Y. Li, L. Xiao, and Y. Sheng, "Virtual laboratory platform for computer science curricula," in Frontiers in Education Conference (FIE), 2015 IEEE, 2015, pp. 1-7.

[8] M. E. Ahmed and S. Hasegawa, "An Instructional Design Model and Criteria for Designing and Developing Online Virtual Labs," International Journal of Digital Information and Wireless Communications (IJDIWC), vol. 4, pp. 355-371, 2014.

[9] Open Source Initiative. (2012). The Open Source Definition. Available: https://opensource.org/osd

[10] W. H. Hsu, "Creating Open Source Lecture Materials: A Guide to Trends, Technologies, and," STEM Education: Concepts, Methodologies, Tools, and Applications, p. 68, 2014.

[11] U. Ruhi, "An experiential learning pedagogical framework for enterprise systems education in business schools," The International Journal of Management Education, vol. 14, pp. 198-211, 2016.

[12] K. Shah, A. Ghosh, M. Hossain, and Y. Lee, "Enhancing Engineering Educational Using Virtual Lab Technology," Retrieved December 04th, 2014.

[13] D. Wu, J. Fulmer, and S. Johnson, "Teaching information security with virtual laboratories," in Innovative Practices in Teaching Information Sciences and Technology, ed: Springer, 2014, pp. 179-192.

[14] P. Kumar, P. Devi, and H. Rohil, "Cloud Computing based Computer Science Lab: Laboratory-as-a-Service," 2015.

[15] moodle.org.(2017). About Moodle. Available: https://docs.moodle.org /34/en/About_Moodle

[16] Autor. ATutor LMS Learning Management System. Available: http://www.atutor.ca/index.php

[17] M. R. Blake and C. Morse, "Keeping your options open: A review of open source and free technologies for instructional use in higher education," Reference Services Review, vol. 44, pp. 375-389, 2016.

[18] P. Brusilovsky, S. Edwards, A. Kumar, L. Malmi, L. Benotti, D. Buck, et al., "Increasing adoption of smart learning content for computer science education," in Proceedings of the Working Group Reports of the 2014 on Innovation \& Technology in Computer Science Education Conference, 2014, pp. 31-57.

[19] M. Ivanović, S. Xinogalos, T. Pitner, and M. Savić, "Technology enhanced learning in programming courses-international perspective," Education and Information Technologies, vol. 22, pp. 2981-3003, 2017.

[20] J. E. Froyd, P. C. Wankat, and K. A. Smith, "Five major shifts in 100 years of engineering education," Proceedings of the IEEE, vol. 100, pp. 1344-1360, 2012.

[21] Apache Friends. XAMPP. Available: https://www.apachefriends.org /index.html

[22] S. MacNeill, L. M. Campbell, and M. Hawksey, "Analytics for Education," Reusing Online Resources: Learning in Open Networks for Work, Life and Education, p. 154, 2014.

[23] V. Venkatesh, M. G. Morris, G. B. Davis, and F. D. Davis, "User acceptance of information technology: Toward a unified view," MIS quarterly, pp. 425-478, 2003. 